portance of other fields of technology to Britain's economy, the development of nuclear power is itself affected by our failure to provide adequately for road and rail transport development and to deal with the scientific and technical man-power situation with vision and imagination as well as with energy and adequate finance.

If the great opportunities which the development of nuclear power offers to Britain are to be used effectively, more will be required than what Mr. Lloyd described on June 13 as a 'shop window' at the Geneva Conference. The Government must give a positive lead, and make sure that, although the country is not in a position to offer nuclear fuel to the under-developed countries in the way that the United States ean, the world is left in no doubt as to the value of the contribution in plant and technique which Britain can offer. Moreover, the absence of any such restricting legislation as the McMahon Act makes it easier for us to share our knowledge and experience than for the United States; and neither Europe nor the countries in the Colombo Plan should be left unaware of the benefits which Britain can bring them, or her advantage over the United States in this respect.

In all this, something of prestige is at stake, but much more also. For Britain to take full advantage of the possibilities for her economic future which nuclear energy offers, the Government must support the Atomic Energy Authority with a well-thought-out and comprehensive policy; it must be fully alive to what is involved in the way of educational policy and balanced scientific and technological development. It means tackling the problem of science teachers with energy and imagination. It means a programme for the expansion of technological and technical education, and keeping that expansion in balance with the expansion of university education. It means also close attention to secondary education, so that the supply of school leavers of the appropriate and broad education is to be forthcoming. It means attention to the nation's resources in scientific and technical research, and seeing that the development of natural resources as well as those of the public services is kept in balance.

Something of the challenge of the situation is to be glimpsed in Sir Francis Simon's article. Already Britain possesses in the Advisory Council on Scientific Policy and in other bodies much of the organization required. Some changes, however, may well be required, for example, in the responsibilities for university and technological and technical education, as between the Minister of Education, the Lord President of the Council and the University Grants Cornmittee; and if the opportunities are to be used, there is much work to be done by the voluntary bodies. It can at least be hoped that the International Conference on the Peaceful Uses of Nuclear Energy will bring home to professional bodies generally the great opportunities which such developments hold for Britain's economic future, and that they will neglect no opportunity of securing the energetic and imaginative action which the prospect demands.

\section{MAGNETODYNAMIC COSMOGONY}

On the Origin of the Solar System

By Prof. H. Alfvén. (The International Series of Monographs on Physics.) Pp. vi+194. (Oxford : Clarendon Press ; London : Oxford University Press, 1954.) 30s. net.

$7 \mathrm{HE}$ author is presenting here a new theory of the establishment and evolution of the solar system. $\mathrm{H}_{\theta}$ is well known for his contributions to electro- and magneto-dynamics, and he makes such processes play a major part here, too. The book is a very valuable source of suggestions of subtle processes that may be of relevance to this and other problems ; and it serves to remind that a wide range of complicated electromagnetic effects may have to be understood for the solution of many astronomical problems. If the discussion is uncertain and speculative for including such effects, others are for leaving them out. No criticism should attach to that.

But if the work is to be regarded as a complete theory of the derivation of the solar system, and this is clearly what the author intends, then each one of the chain of processes or events would have to be shown to have at least a high degree of plausibility. This has not been accomplished. A major link in the chain concerns the separation by diffusion of the different constituents of a gas cloud. It is suggested that a large cloud $\left(10^{17} \mathrm{~cm}\right.$.) is suspended against solar gravity by a magnetic field, and a very strong dipole moment of the early Sun is assumed. The gravitational force would then act on the nonionized constituent, and this would diffuse inwards relative to the ionized component which would be magnetically held. Late in the book there is a brief mention of the importance of the linkage of the lines of force, stating that the lines of force necessary to support the gas against gravity must not tink the cloud and the Sun. Indeed, this is a vital point, for a field of solar origin must inevitably link the Sun; it cannot then support the cloud but only slightly delay its infall by re-routing the material slong longer paths. But the diffusive separation requires some $10^{\circ}$ years and therefore a high stability of the configuration. It is hard to see why the solar field was introduced in that discussion. An alternative support is briefly mentioned; this is a magnetic field of interstellar clouds of gas. Such a field will not link the Sun, and could, if of adequate strength, give the desired support. But it can do so only if its lines of force are effectively anchored in gas far away and unaffected by the solar gravitation. But by linking the gas to interstellar material one is even further from any possibility of extreme stability with a motion of less than $10^{17} \mathrm{~cm}$. in $10^{9}$ years. The average velocities between stars and gas clouds are $10^{4}$ or $10^{5}$ times as high. Not only is the requirement not obtained in this way, but indeed it is hard to see how an extended gaseous mass surrounding the Sun could resist the interstellar streams, even if it is not magnetically connected to them.

There are other links in the chain of processes that one would like to see more fully discussed. The mechanism of transfer of angular momentum to a disk surrounding the Sun has long featured as a central problem in the subject; it may be that a magnetic interaction with the Sun is responsible, but the process will have to be understood, and the limit of its effectiveness evaluated. THomas Gor. 